\title{
Language acquisition through massive open online courses (MOOCs): opportunities and restrictions in educational university environment
}

\author{
Alexandra A. Vorobyeva
}

DOI: 10.18355/XL.2018.11.02.11

\begin{abstract}
The article addresses the issue of the use of massive open online courses (MOOCs) in modern universities, their effectiveness in general as well as the restrictions MOOCs have in terms of allowing students to form the same level or a comparable level of competence in studying of various disciplines as the full-time study provides. The author focuses on the implementation of MOOCs in language acquisition and provides empirical study data on the phenomena linked to language acquisition in terms of both didactic aspects of conveying information and of personality traits of the students that are connected to academic achievement. The data presented in the article suggests that the current state of MOOCs is still inadequate to provide a quality language acquisition in most students as well as setting up a problem of development of better tools to use in MOOCs in terms of acquiring new language and forming a set of independent learning competencies in students. The author provides specific restrictions and outlines possible solutions and the technologies that can be used to improve language acquisition via self-paced courses.

Key words: massive open online course, MOOC, language acquisition, Five-Factor model, personality traits, academic achievement
\end{abstract}

\section{Introduction}

In the latest years, massive open online courses (MOOCs) have grown in popularity both among students and teachers as this method of study provides the former with an opportunity to learn a new skill or acquire a new competency in the comfort of their own home (or anywhere else if they so choose). The latter can create a course once and use it for teaching their full-time students as an additional means of conveying information as well as teaching people around the world (Galushkin, 2015; Cao, Kirilova, Grunis, 2017; Chen et al., 2017; Birova, Vasbieva, Masalimova, 2017; Li, Pyrkova, Ryabova, 2017; Wang et al., 2018). MOOCs usually provide systems of tests and tasks that can be checked automatically thus reducing the workload of teachers (Pappano, 2012; Stacey, 2013; Teixeira et al., 2017).

Universities, as well as government bodies regulating education in a given country, have also been quite enthusiastic about the use of MOOCs in teaching as these courses can be seen as a way of providing students with the best training from top universities, both domestic and international (Garrido et al., 2016; McGreal, Anderson, Conrad, 2015; Aydin, 2017).

Language acquisition in this respect seems to be the logical choice to be converted into a MOOC format as speaking multiple (or at least two) languages is no longer just an advantage a person can have when it comes to leaving school or university but rather a requirement for any young professional even if they are not going to work in a different country or for an international company.

However, the studies show that as MOOCs are a relatively new way of competency formation, these courses are far from perfection or, sometimes, even from a reasonably acceptable quality (Qian, Bax, 2017). In this article, the author strives to take a look at what MOOCs can provide from the standpoint of psychology and theory of education in general and applied to language acquisition. 


\section{Methodology}

The aim of the study is to determine specific features that ensure the effectiveness of MOOC use in competency formation as well as restrictions these courses have, especially in language acquisition, and to outline possible directions of improvement and technologies that need to be implemented for said improvement.

A systematic literature review posed the following research question.

Can MOOCs be effectively used as a stand-alone means of language acquisition or do they require other methods of teaching to ensure successful competency formation and high quality of the learning outcomes?

A review of the literature was undertaken to collect and synthesize studies of language acquisition through MOOCs.

In addition, the data gathered through the systemic literature review was compared to the author's original research in the field of academic achievement in language acquisition based on certain personality traits.

In this article, the author focuses on psychological, didactic, and pedagogical aspects of language acquisition.

\section{Results}

\subsection{Massive Open Online Courses and Their Use in Modern Universities}

Mass open online courses are training courses with mass interactive participation using e-learning technologies and open access through the Internet and are one of the forms of distance education. This format has become popular in the last years with the help of numerous MOOC platforms and universities creating such courses (Kaplan, Haenlein, 2016; Qian, Bax, 2017).

As additions to the traditional materials of the training course, such as video, text materials for independent reading, and homework, massive open online courses provide an opportunity to use interactive user forums that help create and maintain communities of students, teachers, and assistants.

Mass open online courses appeared in the field of distance learning in 2008, but became popular in 2012, when such projects as Coursera, Udacity, and Udemy attracted the first investments (Lewin, 2013).

Early MOOC platforms (for example, Udacity) often advocated the concept of open access (open content). Later sites made access to content paid, leaving the possibility of full or partial free training. Nowadays most courses are partially free (usually the course itself is free, but the certification at the end is a paid service) (Wiley, 2012).

There some forms of training that predate MOOCs as a format. Video lectures from various educational institutions began to appear on the Internet back in the late 1990s, but only the massive open online courses that appeared for the first time at the beginning of 2010 provided interactive communication between students and teachers, as well as taking exams online. Similar platforms were designed for students of different levels of training - both for beginners and experienced students.

Modern MOOCs can attract thousands of students in every batch (usually there is new batch every 2-3 months). There are online universities and schools that operate on the distant learning basis and let students obtain their degrees using a more intricate system of interconnected MOOCs.

MOOCs are usually used vie specially designed platforms, which can be international, regional or even local (as in a platform of a specific university or school). There are regional MOOCs taught in national languages and focused on solving the problems of a particular country or region. Often funding for such resources is provided by government agencies, for example, the Mexican Ministry of Education finances the MéxicoX platform, the French Ministry of National Education supports the FUN (France Université Numérique) platform, and the Ministry of Human Resources 
Development of India funds the NPTEL project (National Program on Technology Enhanced Learning), etc. (Dhawal, 2017).

Funding is an important issue when it comes to MOOCs as the creation, implementation, and support of even a single course is quite extensive as one has to create the content for the MOOC which usually includes a lot of high-quality videos, presentations, tests, texts, interactive tasks and so on. The cost of a single MOOC is usually estimated at around $\$ 50000$ (Kaplan, Haenlein, 2016).

Considering that MOOCs are not the most lucrative industry and they will become even less so in the next few years, as seen in Fig.1., (Adkins, 2016), universities have to look for external funding to create such courses (Belleflamme, Jacqmin, 2016). Unfortunately, sometimes universities cannot refuse to participate in MOOC creation as there are "forced" into it by the government that wants to join the trend. That result in marked growth in the number of MOOCs offered on various platforms.

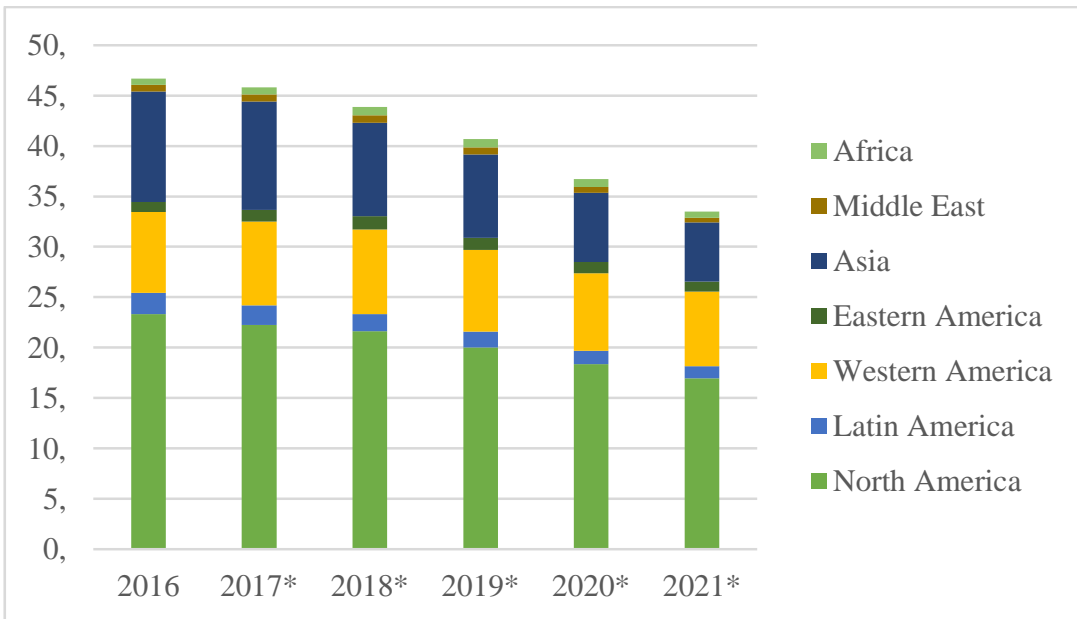

Figure 1: Worldwide self-paced e-learning market revenue from 2016 to 2021, by region (in billion U.S. dollars); * marks the prognosis for the next year

Nonetheless, MOOCs are considered a popular format even though statistical data suggest otherwise.

According to a study conducted by ECAR on a sample of 50,274 students from 161 institutional sites (Fig. 2), only 5\% of the students successfully completed a MOOC during 2015. 74\% did not know what a MOOC was (Dahlstrom, 2015).

Thus, we see a certain contradiction between how we perceive MOOCs, their popularity and use among students and actual engagement of students in training within this format. The author believes that this contradiction has a number of reasons listed below.

First, when we talk about MOOCs we should consider actual student awareness of their existence. The data given above suggests that only a quarter of students know about this option. To make MOOCs more widely used we should actually tell students about this format (Dahlstrom, 2015).

The consequent idea is that we should provide students with a number of competencies that will allow them to use MOOCs in their training. These competencies may range from basic skills of using a computer and web interfaces to self-management skills as time-management, self-motivation, discipline, etc. as MOOCs are free courses that do not involve any sort of compulsory control. This 
might be one of the trickier elements of MOOC learning as only half of the students starting a course complete it. Of course, there are various reasons for that.

Another thing to consider when we try to engage students in MOOCs is the actual specific needs students have that can be fulfilled by these courses. Usually, students do not want to pay for the certificate of completion as it does not help them in their career or study as employers and universities are not that eager to accept this certificate as a verification of a competency acquired. Thus, students usually get the competency for their own pleasure or need. And in order to do that one does not have to take a MOOC but can look for information on the internet or in a library instead.

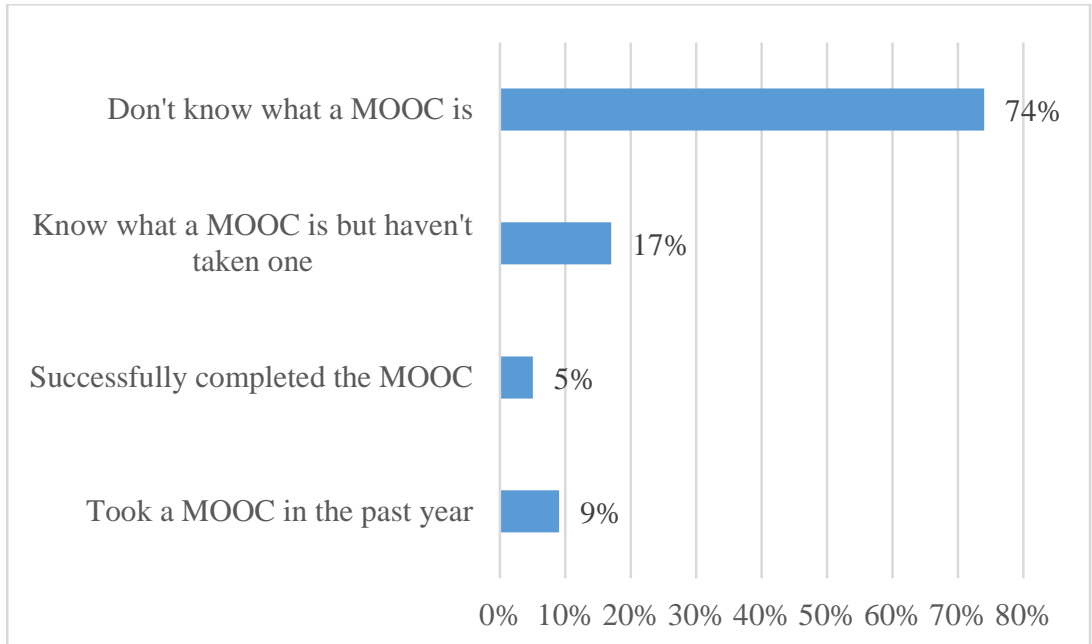

Figure 2: Global student awareness of massive open online courses (MOOC) as of April 2015

This presents us with a question of how to make the MOOCs engaging but not repulsive for the students, what techniques to use and what information to provide. And, of course, whether or not it is going to be effective.

In this article we are focusing on language acquisition thus in the next section we will consider some aspects of language acquisition that can be improved or inhibit this process.

\subsection{Language Acquisition: Didactic Aspects and Personality of the Students}

Foreign language is one of the most common courses taken around the world with the most popular language here being English. Language acquisition is no longer considered a training course one may refuse to take but it is rather a requirement in most universities and schools, and it is certainly a requirement in may jobs. Thus, language acquisition is also one of the most well-studied fields of training (Lidz, Dudley, 2017).

When we acquire a new language in class, we usually focus on the following aspects of language: reading, writing, speaking and listening. These aspects require using sets of specific tasks and activities to develop properly. The activities themselves require some form of feedback from either the instructor or the peer group.

At the same time during the development of these aspects a student is also supposed to acquire proper grammar, vocabulary, and pronunciation, thus language acquisition involves at least seven different features that need to be worked on by the student. Another feature of language acquisition is that it depends not only on didactic aspects

XLinguae, Volume 11, Issue 2, April 2018, ISSN 1337-8384, eISSN 2453-711X 
but also on psychological factors like student's personality traits and group dynamics among the peers (Lidz, Dudley, 2017).

Generally speaking, successful language acquisition requires one to gain theoretical knowledge of the grammar of a particular language, learn a certain number of words and collocations, learn, how to pronounce these words as well as acquire the skill to read texts of various styles, write different types of texts, understand spoken language, and converse with others. This process is sufficiently facilitated by being a part of a community speaking the language as one is immersed in the language environment and is somewhat hindered if one has no opportunity to practice language outside of the classroom (Lidz, Dudley, 2017).

Thus, self-paced language acquisition is a hard task to manage in terms of didactic aspects alone.

We should also note that success of language acquisition depends on certain psychological factors and predispositions the students have. These features should be kept in mind when designing tasks and activities for MOOCs. Another important note here is that MOOCs allow one to measure said success by students' academic achievement that was found to be linked to various traits of their personality. Our original research shows specific correlations.

The first research was conducted using the Five-Factor Model framework (Novikova, Vorobyeva, 2017). The most commonly used version of the Five-Factor Model (FFM) is developed by R.R. McCrae, O.P. John (1992) in 1992 and is based upon a number of the previous studies (Goldberg, 1992; McCrae, John, 1992; Digman, 1997). The FFM framework states that the factors (personality traits) are orthogonal and comprise 6 facets each. The FFM include such factors as Neuroticism, Extraversion, Openness to experience, Agreeableness, and Conscientiousness (Furnham, Heaven, 1999; Vorobyeva, 2011; Novikova, 2013).

A considerable amount of empirical research based on the FFM model has detected correlations between academic achievement and personality traits in students. A high predictive power of FFM traits in evaluating academic achievement was discovered (Furnham, Moutafi, Chamorro-Premuzic, 2005; Ackerman, Chamorro-Premuzic, Furnham, 2011; Rosander, Bäckström, Stenberg, 2011). According to the research data, Conscientiousness and Openness are highly associated with academic achievement in university students (O'Connor, Paunonen, 2007; Poropat, 2009).

A total of 207 respondents took part in the research, including 41 young men and 166 young women. All the respondents were the first and second-year Russian students of Linguistics department of the Peoples' Friendship University of Russia (PFUR). The age of the respondents is from 17 to 25 years; the average age is 19 years. They were advised that participation would be free and voluntary.

The NEO Five-Factor Inventory (NEO-FFI) that is considered as the most commonly used versions of the Big Five personality inventories was used to establish the FFM traits of the subjects (Costa, McCrae, 1989).

The results of the study suggest that Consciousness and Openness are indeed the main personality factors when it comes to academic achievement, especially for language acquisition (Novikova, Vorobyeva, 2017).

The second study was conducted using the system-functional approach of Y.V. Kozhukhova (2011) in terms of persistence as a personality trait. We measured the students' performance on the following parameters: Phonetics, Grammar, Speaking, and Political vocabulary. Apart from these parameters we also took into account their general academic achievement (GPA). The sample of the research consisted of 115 students of RUDN University.

The results of this study suggest that persistence as a trait closely linked to Consciousness shows correlation with such aspects of language acquisition as Phonetics and Speaking (Krupnov, Kozhukhova, Vorobyeva, 2017). 
This research suggests that language acquisition requires among other aspects a student's ability to motivate themselves to continue with the study. This motivation, of course, can be external and come from the setting in which language is acquired, such as in the classroom (Barak, Watted, Haick, 2016).

Thus, even on the level of personality traits student require specific types of activity that will take into account various forms of language mastery. These activities may not be available in a MOOC format. Also, being self-paced courses, MOOCs have a higher dropout rate, which may prove especially true in language courses as without constant feedback one might find themselves in a situation when the need to complete a MOOC is lacking due to lack of favourable results.

\subsection{MOOCs and Language Acquisition}

As we can see, language acquisition implies a lot of specific aspects that should be worked upon in a cooperative way that includes a presence of an instructor who both speaks the language and know how to teach this language as a foreign and a presence of a peer group that will allow practicing language on the spot.

Unfortunately, MOOCs as of now are not designed to incorporate all the aspects needed for successful language acquisition (Kulkarni et al., 2015).

For example, learning grammar of a language can be done by the student independently provided the language they are studying resembles their native one or the one they are fluent in (usually the language of the same group). But learning a new type of grammar may require additional instruction that is not always available in a MOOC with thousands of people. Studies show that in these cases students of A MOOC tend to divide into smaller groups that continue their communication and learning outside of MOOC environment (Jarvis , Krashen, 2014; de Larreta-Azelain, 2014). Unfortunately, these groups do not include a native speaker to correct their grammar mistakes.

When it comes to phonetics, MOOCs are not as helpful either as the correct phonetics takes a lot of time to be learnt and usually, this requires constant feedback from the instructor as well as a lot of practice. MOOCs at this point do not provide quality feedback as speech recognition technology itself is far from perfect, and sometimes even native speakers cannot use this technology without errors on the software part (Jarvis, Krashen, 2014; Rubio, 2014).

Vocabulary, however, can be built using MOOC technologies with success comparable to full-time learning with an instructor as this part of language acquisition is fairly independent. Stylistic and semantic commentary can be easily built into a MOOC in the text, video, or even conversational activity form (Viswanathan, 2012).

If we consider reading, writing, listening, and speaking aspects of language acquisition, we may conclude that reading competency may as well be acquired as a part of MOOC as this competency is one of the most suitable for independent learning. However, assessment of its formation on early stages of learning still requires quality feedback from the instructor and fellow students.

Writing as an "active" speech aspect requires more feedback from the instructor especially when it comes to specific styles of writing, such as essays, formal and informal letters, scientific texts, etc. This competency may be formed using a MOOC or, rather, a set of MOOCs aimed at different styles of writing. However, this is a suitable format.

Listening is similar to reading in many respects when it comes to competency formation from a didactic standpoint. All things considered, this competency may be the easiest one to form using MOOC format, however in order to create the tasks and activities requires, the author of the course requires a lot of time and preparation. Which is why in classroom instructors mostly use authorized tapes and recordings as well as films and movies and, of course, their own voice. Copyright laws usually

XLinguae, Volume 11, Issue 2, April 2018, ISSN 1337-8384, eISSN 2453-711X 
prohibit instructors from using authorized recordings or films or parts thereof in MOOCs, therefore, the authors need to create their own content, a process both timeconsuming and expensive. Which is why listening is not as easy to implement in MOOC as one may initially believe.

Speaking is probably the hardest aspect to implement within MOOC format as it requires formation of not only the correct pronunciation, intonation, speech pattern, etc. but also an ability to converse with others conveying ideas and understanding the meaning of sentences as well as an ability of reacting to the information learnt in a conversation quickly and precisely. These skills require a "live" audience or a least a pair of speakers which is not usually possible during a self-paced course as there may be no speaking partners available at the moment for a student but also because here we have to admit the existence of certain technical limitations such as lack of eye-toeye contact that allows participating in a conversation much more effective than a talk on the phone or using a similar voice chat. Even the use of a web camera cannot be equated to a real conversation in terms of language acquisition. Of course, students do practice speaking with each other, but research suggests that these are not ideal conditions for the early stages of language acquisition.

Thus, creating a MOOC that will allow students acquire language as good as learning in a classroom can seems virtually impossible as MOOCs at this point are not equipped with the technology to effectively form basic language competences. Another issue here is the need to acquire language through specific MOOCs as language schools and courses are available in most parts of the world, plus there are numerous non-MOOC resources on the internet one may use to their own convenience including resources allowing to find native people who want to engage in a conversation with a student (typically in exchange for language practice in the learner's native language).

There are, however, certain types of language MOOCs that seem to fit the format properly.

\section{Discussion and Conclusion}

What is the niche for language MOOCs? Considering all the restrictions described above, we believe MOOCs to be rather ineffective at the early stages of language acquisition as these stages require more personal attention and feedback from the instructor. However, there are certain types of language MOOCs that seem quite effective compared to traditional classroom learning.

First, we may list "complementary" MOOCs, that allow students to acquire competencies in addition to classroom learning. Here almost any entry-level language MOOC can be used as students use this information to complement the skills they get in person with their instructors.

Another type of MOOC may be the "special" MOOC focusing on certain aspects of language acquisition, such as creative writing in another language, collocations, idioms, specific writing styles (e.g. scientific language), specific vocabulary and situations (e.g. business language), etc.

We believe "advanced language" MOOCs can be a good option as they target students with certain base language and can build upon this foundation as this requires slightly less feedback and the tools of MOOC are adequate in the provision of such feedback.

The last niche for language MOOCs we would like to point out is the "rare language" niche. We have mentioned that language education is available in most countries of the world but unfortunately this education usually consists of such options as popular languages (English, French, Spanish, etc.), UN languages (aforementioned language plus Russian, Arabic, Mandarin), "vogue" languages (these differ according to country and time period, e.g. Japanese, Korean, Portuguese, etc.). Rarer languages are harder to acquire as there is a smaller number of speakers who can teach students in the classroom. However, even an entry-level MOOC can be beneficial for such 
languages. Naturally, the creators would have to consider all the restrictions such MOOC have and work around them. Such MOOC would be more expensive to make as well, but it would be helpful for people in different countries. Another advantage of the creation of such courses is that they could allow to bring attention to lesser-known languages which oftentimes have unique grammar structure, phonetics, and vocabulary. In some cases, that could even help to preserve a language or rejuvenate it. We believe that such courses could be included into cultural heritage preservation and probably even receive funding from governments or special culture preservation funds as this would allow for preservation as well as raising awareness of the language and people who speak it.

It is also worth mentioning that some of the restrictions of language MOOCs can be overcome by use of different MOOC technologies, such as smaller groups, better use of video chats for students and instructors, more interactive tasks including those going beyond traditional textbook exercises as well as the creation of new language training specific technologies. Such technologies, however, are beyond the scope of this article and should be developed in conjunction with IT specialists. The author believes these technologies would be of interest and of demand in the next few years unless the technology of automated translation transcends the need of actually learning another language.

In this article, we have addressed some limitations and restrictions massive open online courses have in general as well as specific restrictions of their use in language acquisition.

These restrictions are linked to didactic aspects of language training, psychological predispositions of students, and technical limitations modern MOOCs possess.

In order to create effective language, MOOCs four niches are suggested. Technological advancements that allow the creation of more effective MOOCs are briefly described.

In conclusion, we would like to add that speaking multiple languages will likely remain a valuable skill and the demand for effective training courses will increase in the following years.

\section{Acknowledgments}

The publication has been prepared with the support of the "RUDN University Program 5-100".

\section{Bibliographic references}

ACKERMAN, P.L. - CHAMORRO-PREMUZIC, T. - FURNHAM, A. 2011. Trait complexes and academic achievement: Old and new ways of examining personality in educational contexts. In: British Journal of Educational Psychology, vol. 81, pp. 2740. ISSN 0007-0998.

ADKINS, S.S. 2016. The 2016-2021 worldwide self-paced eLearning market: The global eLearning market is in steep decline. In: Ambient Insight. Retrieved from: http://www.ambientinsight.com/Resources/Documents/AmbientInsight_20152020_US_Self-paced-eLearning_Market_Abstract.pdf

AYDIN, C.H. 2017. Current status of the MOOC movement in the world and reaction of the Turkish higher education institutions. In: Open Praxis, vol. 9, pp. 59-78. ISSN 1369-9997.

BARAK, M. - WATTED, A. - HAICK, H. 2016. Motivation to learn in massive open online courses: Examining aspects of language and social engagement. In: Computers \& Education, vol. 94, pp. 49-60. ISSN 03601315. 
BELLEFLAMME, P. - JACQMIN, J. 2016. An economic appraisal of MOOC platforms: business models and impacts on higher education. In: CESifo Economic Studies, vol. 62, pp. 148-169. ISSN 1612-7501.

BIROVA, J. - VASBIEVA, D.G. - MASALIMOVA, A.R. 2017. Communication in French foreign language learning by implementing the aspects of interculturality. In: Communications - Scientific Letters of the University of Zilina, vol.19, n. 4, pp. 95104. ISSN:1335-4205.

CAO, Y. - KIRILOVA, G.I. - GRUNIS, M.L. 2017. Cooperative Research Projects of Master's Students (Education Programs) in the Open Informational Educational Environment. In: EURASIA Journal of Mathematics, Science and Technology Education, vol. 13, n. 7, pp. 2859-2868. ISSN: 13058215, 13058223.

CHEN, F. - GORBUNOVA, N.V. - MASALIMOVA, A.R. - BIROVA, J. 2017. Formation of ICT-Competence of Future University School Teachers. In: EURASIA Journal of Mathematics, Science and Technology Education, vol. 13, n. 8, pp. 47654777. ISSN: $13058215,13058223$.

COSTA, P.T. - MCCRAE, R.R. 1989. The NEO Five Factor Inventory. Odessa, FL: Psychological Assessment Resources. ISBN-13: 978-9997924452

DAHLSTROM, E. 2015. Educational technology and faculty development in higher education. Research report. Louisville: ECAR. ISBN 0766059782

DE LARRETA-AZELAIN, M.D. 2014. Language Teaching in MOOCs: the Integral Role of the Instructor. In: Language MOOCs: Providing learning, transcending boundaries, vol.1, pp. 67-90. ISBN 9783110422504.

DHAWAL, S. 2017. Massive List of MOOC Providers Around the World. Where to Find MOOCs: The Definitive Guide to MOOC Providers. Available online: https://www.class-central.com/report/mooc-providers-list/

DIGMAN, J.M. 1997. Higher-order factors of the Big Five. In: Journal of Personality and Social Psychology, vol. 73, pp. 1246-1256. ISSN 00223514.

FURNHAM, A. - HEAVEN, P. 1999. Personality and social behaviour. London: Arnold. ISBN-13: 978-0340677254.

FURNHAM, A. - MOUTAFI, J. - CHAMORRO-PREMUZIC, T. 2005. Personality and Intelligence: Gender, the Big Five, Self-Estimated and Psychometric Intelligence. In: International Journal of Selection and Assessment, vol. 13, pp. 11-24. ISSN 0965075X.

GALUSHKIN, A.A. 2015. Education in the field of national information security in the Russian federation and abroad. In: Journal of Computer Science, vol. 11, n. 10, pp. 988-994. ISSN: 1549-3636.

TSVETKOVA, M.I. 2017, The Speed Reading is in Disrepute: Advantages of Slow Reading for the Information Equilibrium. European Journal of Contemporary Education, vol. 6, n. 3, pp. 593-603. DOI: 10.13187/ejced.2017.3.593

GARRIDO, M. - KOEPKE, L. - ANDERSON, S. - FELIPE MENA, A. MACAPAGAL, M. - DALVIT, L. 2016. The Advancing MOOCs for Development Initiative: An examination of MOOC usage for professional workforce development outcomes in Colombia, the Philippines, \& South Africa. Available online: https://www.irex.org/sites/default/files/node/resource/examination-mooc-usage-

professional-workforce-development-outcomes.pdf.

GOLDBERG, L.R. 1992. The development of markers for the Big-Five factor structure. In: Psychological Assessment, vol. 4, n. 1, pp. 26-42. ISSN 10403590. Available online: https://library. educause. edu/ /media/files/library/2015/6/ers1507pdf.

JARVIS, H. - KRASHEN, S. 2014. Is CALL obsolete? Language acquisition and language learning revisited in a digital age. In: Tesl-Ej, vol. 17, n. 4. ISSN 1072-4303. KAPLAN, A.M. - HAENLEIN, M. 2016. Higher education and the digital revolution: About MOOCs, SPOCs, social media, and the Cookie Monster. In: Business Horizons, vol. 59, n. 4, pp. 441-450. ISSN 0007-6813. 
KOZHUKHOVA, Y.V. 2011. Quantitative and qualitative characteristics of persistence of students with different levels of progress in foreign language learning. In: Bulletin of Peoples' Friendship University of Russia. Series: Psychology and Pedagogics, vol. 1, pp. 78-82. ISSN: 2313-1683.

KRUPNOV, A.I. - KOZHUKHOVA, Y.V. - VOROBYEVA, A.A. 2017. Persistence and Academic Achievement in Foreign Language in Natural Sciences Students. In: RUDN Journal of Psychology and Pedagogics, vol. 14, pp. 143-154. ISSN: 23131683.

KULKARNI, C. - WEI, K.P. - LE, H. - CHIA, D. - PAPADOPOULOS, K. CHENG, J. - KOLLER, D. - KLEMMER, S.R. 2015. Peer and self assessment in massive online classes. ACM Transactions on Computer-Human Interaction. Springer, Cham. ISBN 978-3-319-06822-0.

LEWIN, T. 2013. Universities abroad join partnerships on the web. In: The New York Times, vol. 20, pp. 21-02. ISSN 0362-4331.

LI, N. - PYRKOVA, K.V. - RYABOVA, T.V. 2017. Teaching Communication Skills and Decision-Making to University Students. In: EURASIA Journal of Mathematics, Science and Technology Education, vol. 13, n. 8, pp. 4715-4723. ISSN: $13058215,13058223$.

LIDZ, J. - DUDLEY, R. 2017. Evaluation measures and the study of language acquisition. In: Language Acquisition, vol. 24, pp. 81-84. ISSN 1532-7817.

MCCRAE, R.R. - JOHN, O.P. 1992. An introduction to the Five-Factor model and its applications. In: Journal of Personality, vol. 60, n. 2, pp. 175-215. ISSN 00223506.

MCGREAL, R. - ANDERSON, T. - CONRAD, D. 2015. Open educational resources in Canada 2015. In: The International Review of Research in Open and Distributed Learning, vol. 16, n. 5, 744-757.

NOVIKOVA, I.A. - VOROBYEVA, A.A. 2017. Big Five Factors and academic achievement in Russian students. In: Psychology in Russia: State of the Art, vol. 10, n. 4, pp. 95-106. ISSN 2074-6857.

NOVIKOVA, I.A. 2013. Big Five. New Jersey: Wiley-Blackwell. ISBN-13: 9780470671269.

O'CONNOR, M.C. - PAUNONEN, S.V. 2007. Big Five personality predictors of post-secondary academic performance. In: Personality and Individual Differences, vol. 43, pp. 971-990. ISSN 0191-8869.

PAPPANO, L. 2012. The Year of the MOOC. In: The New York Times, vol. 2, $352-$ 368. ISSN 0362-4331.

POROPAT, A.E. 2009. A meta-analysis of the five-factor model of personality and academic performance. In: Psychological Bulletin, vol.135, pp. 322-338. ISSN 00332909.

QIAN, K. - BAX, S. 2017. Beyond the language classroom: researching MOOCs and other innovations. Dublin: Research-publishing. net. ISBN-13: 978-1908416520

ROSANDER, P. - BACKSTROM, M. - STENBERG, G. 2011. Personality traits and general intelligence as predictors of academic performance: A structural equation modeling approach. In: Learning and Individual Differences, vol. 21, pp. 590-596. ISSN 10416080.

RUBIO, F. 2014. Teaching pronunciation and comprehensibility in a language MOOC. In: Language MOOCs: Providing learning, transcending boundaries, vol. 1, 143-160. ISBN 9783110422504.

STACEY, P. 2013. The pedagogy of MOOCs. In: The International Journal for Innovation and Quality in Learning, vol. 3, pp. 111-115. ISSN 1471-8197 8

TEIXEIRA, A. - AYDIN, C. - SCHUWER, R. - JANSEN, D. 2017. Comparing MOOC Adoption Strategies in Europe. In: International Review of Research in Open and Distributed Learning, vol. 16, pp. 116-136. ISSN 1492-3831.

XLinguae, Volume 11, Issue 2, April 2018, ISSN 1337-8384, eISSN 2453-711X 
TYUNNIKOV, Y.S. 2017,Classification of Innovation Objectives set for Continuing Professional Teacher Development. European Journal of Contemporary Education, vol. 6 n. 1: pp. 167-181. DOI: 10.13187/ejced.2017.1.167

VISWANATHAN, R. 2012. Teaching and Learning through MOOC. In: Frontiers of Language and Teaching, vol. 3, n. 1, pp. 32-40. ISSN 2167-8642.

VOROBYEVA, A.A. 2011. The Five-Factor Model: General Overview. Bulletin of Peoples' Friendship University of Russia. Series: Psychology and Pedagogics, vol. 4, pp. 80-86. ISSN: 2313-1683.

WANG, S. - GORBUNOVA, N.V. - MASALIMOVA, A.R. - BIROVA, J. SERGEEVA, M.G. 2018. Formation of Academic Mobility of Future Foreign Language Teachers by Means of Media Education Technologies. EURASIA Journal of Mathematics, Science and Technology Education, vol. 14, n. 3, pp. 959-976. ISSN: $13058215,13058223$.

WILEY, D. A. 2012. The MOOC misnomer. Available online: https://opencontent.org/blog/archives/2436.

Words: 5284

Characters: $34686(19,27$ standard pages)

Assoc. Prof. Alexandra A. Vorobyeva, PhD

Department of Social Pedagogy

Institute of Foreign Languages

RUDN University (Peoples' Friendship University of Russia)

6, Miklukho-Maklay str.

117198 Moscow

Russia

vorobyeva_aa@rudn.university 